\title{
Implementasi Knowledge Management System Pada Rumah Sakit Muhammadiyah Palembang Berbasis Web (Study Kasus: Unit Sumber Daya Manusia)
}

\author{
Brilian Sidhatama $^{1}$, Fatmasari' ${ }^{2}$ Imam Solikin $^{3}$ \\ 1,2Information System Department, Bina Darma University, Palembang, Indonesia \\ ${ }^{3}$ Vocational Department, Bina Darma University, Palembang, Indonesia \\ Email: 'briliansidhatama11@gmail.com, ${ }^{2}$ fatmasari@mail.binadarma.ac.id, \\ 3imamsolikin@binadarma.ac.id
}

\begin{abstract}
Abstrak
Knowledge pada era informasi ini sangat penting bagi perusahaan Pada Administrasi rumah sakit muhammadiyah Palembang ini memiliki asset pengetahuan yang penting yaitu tacit knowledge dan explicit knowledge. Namun sayang, Knowledge Sharing yang ada di rumah sakit muhammadiyah Palembang ini belum berjalan dengan baik dimana tacit knowledge hanya dimiliki oleh karyawan tertentu, dan explicit knowledge seperti dokumen yang tersimpan di berbagai tempat penyimpanan. Solusi dari permasalahan tersebut yaitu membangun KMS bagian administrasi pelayanan di rumah sakit muhammadiyah Palembang. KMS pada bagian administrasi ini diperlukan untuk berbagi informasi dan sebagai referensi bagi para karyawan yang membutuhkan Aplikasi KMS yang dibangun menggunakan bahasa pemrograman HTML 5 dan basis data MySQL. Serta dengan menggunakan metode the 10-step knowledge management roadmap. Aplikasi KMS yang dibangun dapat membantu rumah sakit muhammadiyah dalam mengumpulkan pengetahuan tersebut kedalam suatu wadah, sehingga tidak akan kehilangan pengetahuan yang dimiliki karyawan dibagian administrasi.
\end{abstract}

Kata Kunci: KMS, knowledge management roadmap, knowledge sharing

\section{PENDAHULUAN}

Knowledge pada era informasi ini sangat penting bagi perusahaan. Semakin banyak knowledge yang dimiliki oleh karyawan dari sebuah perusahaan, akan membuat perusahaan tersebut semakin maju serta mewariskan pengetahuan kepada orang yang tepat demi meningkatkan kinerja organisasi, pengetahuan itu dibagi menjadi 2 yaitu tacit knowledge dan explicit knowledge. Knowledge Management dapat membantu perusahaan untuk melakukan sharing pengetahuan seputar proses bisnis, masalah-masalah yang terjadi pada setiap unit kerja, hingga berbagi pengalaman tentang hal-hal diluar 
pekerjaan yang bermnfaat bagi pengembangan pengetahuan dari karyawan perusahaan. Knowledge Management adalah sebuah proses yang membantu organisasi dalam mengidentifikasi, memilih, mengorganisasikan, menyebarkan, dan memindahkan informasi penting dan pengalaman yang merupakan bagian dari organisasi (Viju Mattew, 2011). Pada Rumah Sakit Muhammadiyah Palembang, sumber daya manusia (SDM) merupakan salah satu bagian terpenting didalam rumah sakit. Hal ini dikarenakan semua proses bisnis dan pelayanan yang dilakukan oleh rumah sakit memerlukan sumber daya manusia (SDM) yang berkualitas dibidangnya..

Sekarang ini rumah sakit muhammadiyah ketika karyawan berhenti atau masuknya karyawan baru serta mengalami perpindahan divisi unit kerja atau jabatan karyawan, maka tidak diwariskannya pengetahuan dan pengalaman yang dimiliki oleh karyawan tersebut, sehingga terjadinya kehilangan informasi serta pengulangan kesalahan yang ada. Demikian juga untuk karyawan baru yang ingin menjalankan tugas dan tanggung jawab penuh memiliki waktu yang lama untuk mempelajari semua pekerjaan, maka dibutuhkan pendokumentasian agar dapat memperoleh knowledge tersebut. Dan juga sharing knowledge dirumah sakit muhammadiyah belum berjalan dengan baik

Untuk mewujudkan solusi yang perlu diberikan adalah dengan membangun knowledge management system pada Rumah Sakit Muhammadiyah agar tidak lagi terjadinya kehilangan knowledge yang dimiliki oleh karyawan serta menjadi media referensi antar karyawan di dalam rumah sakit, maka dari itu penulis menuangkan penelitiannya dalam bentuk penulisan skripsi yang berjudul Implementasi Knowledge Management System Pada Rumah Sakit Muhammadiyah Berbasis Web.

\section{METODOLOGI PENELITIAN}

\subsection{Metode Pengembangan Sistem}

Metode pengembangan system yang akan digunakan pada implementasi knowledge management system pada rumah sakit muhammadiyah Palembang ini adalah metode 10 step knowledge management roadmap yang dikemukakan oleh Amrit Tiwana (2002) disusun menjadi 4 fase sebagai berikut.

1. Evaluasi infrastruktur

2. Analisis, desain, dan pengembangan KMS

3. System penyebaran

4. Evaluasi 


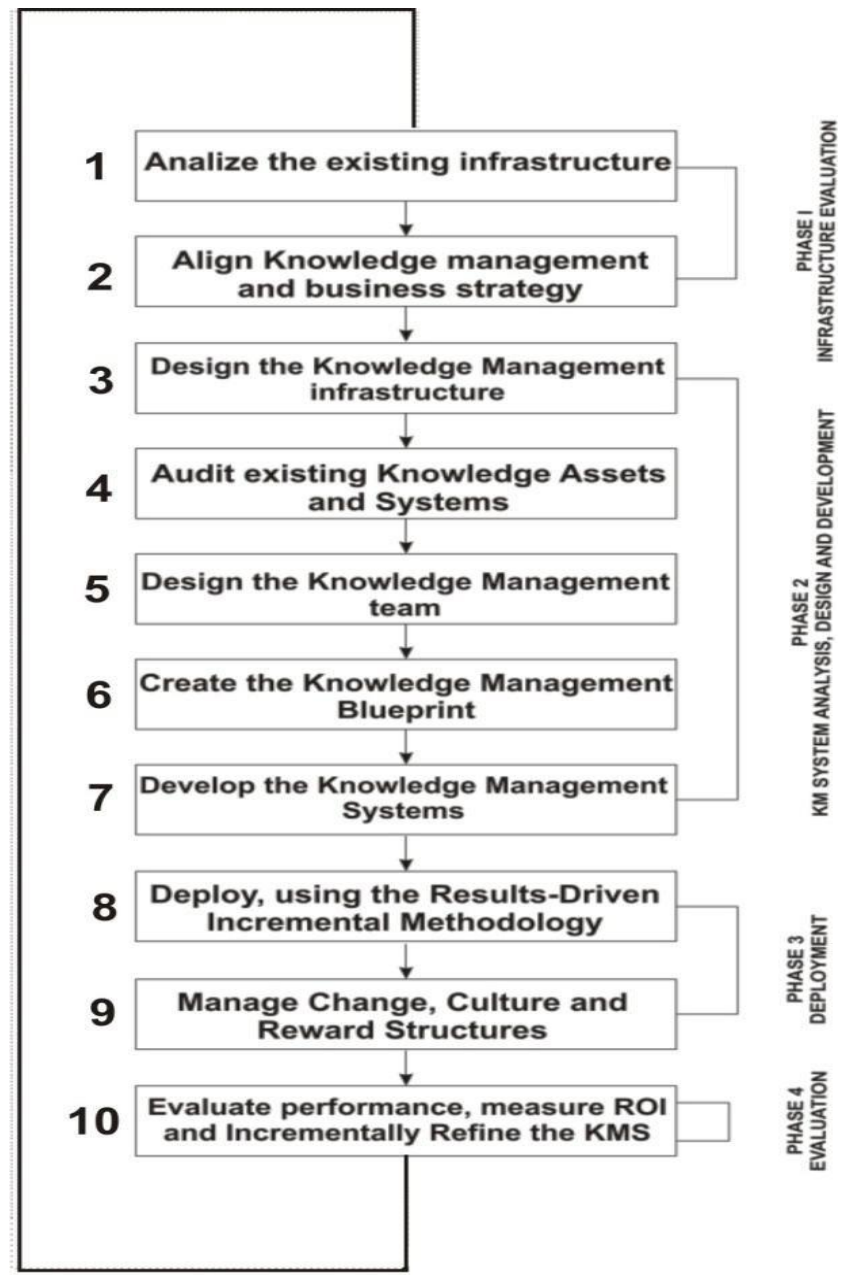

Gambar 1.10 Step Knowledge Management Roadmap (Tiwana, 2002)

Namun pada penelitian yang akan dilakukan penulis pada system ini hanya akan menggunakan fase pertama sampai dengan fase kedua yaitu fase evaluasi infrastruktur, dan analisis desain dan pengembangan knowledge management.

\subsection{Implementasi}

Implementasi merupakan suatu proses penerapan kebijakan atau peraturan yang telah dibuat dan diterapkan dalam suatu rancangan atau program yang telah diusulkan. 


\subsection{Knowledge Management System}

Knowledge Management System adalah proses sistematik untuk menemukan, memilih, mengorganisasikan, menyarikan, dan menyajikan pengetahuan dengan cara tertentu, sehingga para pekerja mampu memanfaatkan dan meningkatkan penguasaan pengetahuan dalam suatu bidang kajian yang spesifik, untuk kemudia ada proses institusional agar pengetahuan yang diciptakan menjadi pengetahuan perusahaan. Berdasarkan pengertian KMS diatas maka dapat disimpulkan bahwa KMS merupakan alat yang ditunjukan untuk mendukung sebuah strategi perusahaan dalam mengumpulkan, mengidentifikasikan, memilih, mengolah dan menyebarkan knowledge yang ada, baik individual knowledge maupun knowledge perusahaan sehingga dapat mendorong pembelajaran dalam organisasi serta terciptanya berbagi pengetahuan antar karyawan.

\subsection{Model SECI}

Knowledge yang di-share dapat menjadi knowledge baru sesudah mengalami proses sosialisasi, eksternalisasi, kombinasi, dan internalisasi (SECI). Knowledge baru sebagai hasil proses sosialisasi, eksternalisasi, kombinasi, dan internalisasi akan mengalami multiplikasi nilai jika mengalami proses SECI secara berkelanjutan. Proses multiplikasi nilai knowledge tersebut dinamakan sebagai proses knowledge spiral, seperti yang ditunjukkan pada gambar di bawah ini.

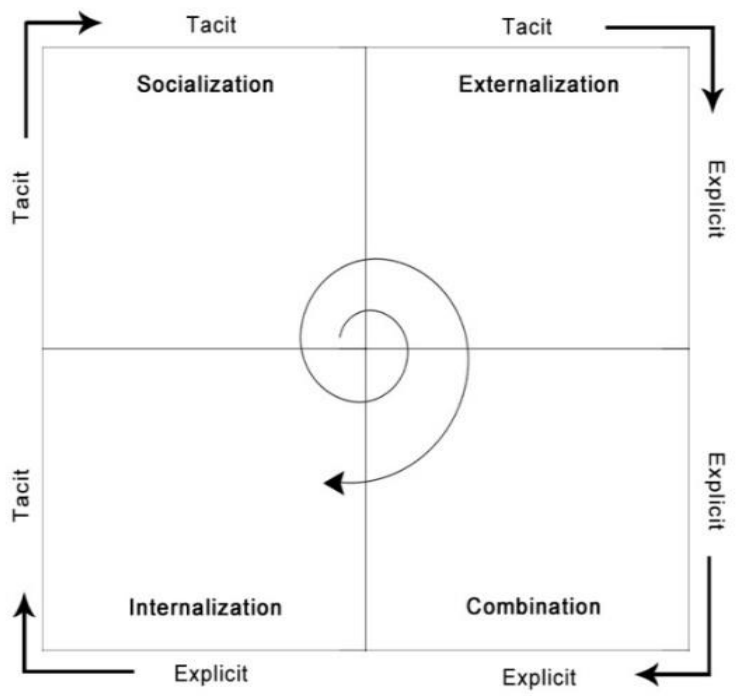

Gambar 2. Model SECI Sumber: Nonaka, et. Al. (1995) 


\section{B. Merancang Tim Knowledge Management}

Melakukan perancangan tim KM dilakukan untuk menentukan siapa yang menggunakan sistem dan yang terlibat didalamnya. Serta menentukan peran dari masing-masing pengguna. Pada fase ini didapatkan 3 kelompok sistem yaitu :

1. Tim KM

Tim Km dibentuk untuk melakukan proses penyeleksian knowledge yang masuk dan juga bertugas untuk menangkap knowledge baru yang ada. Tim KM terdiri dari Kepala Badan Administrasi, Kepala HRD, Kepala Pelayanan Rumah Sakit, Kepala Keuangan Rumah Sakit.

2. Pegawai

Pegawai/karyawan berperan sebagai sumber pengetahuan yang terdiri dari Karyawan administrasi Rumah Sakit Muhammadiyah, Pelayanan Rumah Sakit Muhammadiyah, Pegawai Kuangan Rumah Sakit Muhamadiyah dan Pegawai HRD Rumah Sakit Muhammadiyah Palembang.

3. Admin

Admin berperan sebagai administrator dan juga developer dari sistem. Admin bertanggung jawab atas sistem KMS untuk posisi admin terdiri dari pegawai dengan jabatan perantara komputer.

\section{Membuat Blueprint Knowledge Management System}

Untuk merancang blueprint knowledge management system, peneliti menggunakan acuan 7 layer arsitektur knowledge management dari Tiwana (2002) yang terdiri dari interface layer, application layer, transport layer, middleware and lagecy integration dan Repository

1. Interface layer

Layer ini adalah layer yang menghubungkan pengguna dengan layer yang ada dibawahnya. Pada tahapan sebelumnya dijelaskan bahwa platform yang digunakan untuk menghubungkan sistem dengan pengguna adalah platform yang berbasis internet dan web application, sehingga pegawai dapat terhubung dan berinteraksi dengan web server yang ada pada knowledge management system yang diusulkan maka dari sisi pegawai hanya tinggal memasang peramban untuk mengakses halaman web yang dituju. Peramban merupakan interface layer dari sistem yang diusulkan. Proses pengaksesan informasi melalui peramban terjadi ketika pengguna mengirimkan permintaan kepada web server melakukan pengecekan apakah informasi tersebut tersimpan dalam database server, memberikan respons apabil informasi yang dicari tersedia dan menampilkannya kedalam peramban.

2. Accsess and Authentification Layer

Layar ini membatasi ruang gerak dari pengguna sistem untuk menghindari terjadinya penyalahgunaan wewenang dari pihak tertentu terhadap 
knowledge yang ada dalam sistem. Tabel dibawah ini akan menjelaskan tentang hak akses

3. Collaboration, Filltering and intelligence Layer

Pola pengguna dapat memperoleh knowledge baru dan memberikan kontribusi knowledge ke dalam sistem. Dalam layer ini sistem menyediakan fitu pencarian knowledge. Pemberian tautan pada knowledge digunakan untuk merujuk ke pembahasan yang lebih lengkap. Pada layer ini digunakan model SECI dari Nonake dan Takeuchi (1995), Nonake dan Takeuchi menganggap bahwa pengetahuan merupakan suatu hal yang dinamis dan dapat berubah bentuk antara tacit dan explicit. Mereka kemudian mengusulkan suatu model dalam proses penciptaan pengetahuan, yang kemudian memungkinkan empat langkah penciptaan pengetahuan disebut model SECI atau socialization, extranalization, combination, dan internalization. Berikut ini proses SECI yang ada pada Rumah Sakit Muhammadiyah Palembang.

a. Socialization

Proses sosialisasi antar pegawai di Rumah Sakit Muhammadiyah salah satunya dilakukan malalui pertemuan tatap muka. Melalui pertemuan tatap muka ini pegawai dapat saling berbagi knowledge dan pengalaman yang dimilikinya, sehingga tercipta knowledge baru bagi mereka.

b. Externalization

KMS akan sangat membantu proses eksternalisasi ini, yaitu proses untuk mengartikulasi tacit knowledge menjadi suatu konsep yang jelas pada Rumah Sakit Muhammadiyah Palembang proses ini terjadi saat pegawai menuliskan knowledge dan pengalaman yang didapatkan saat mengerjakan proses . Tulisan ini akan sangat bermanfaat bagi pegawai lain yang sedang memerlukanya.

c. Combination

Combination yaitu mengkombinasikan berbagai explicit knowledge yang berbeda untuk disusun ke dalam KMS di Rumah Sakit Muhammadiyah Palembang proses ini memanfaatkan explicit knowledge yang sudah ada untuk diimplementasikan menjadi explicit knowledge baru yang lebih bermanfaat.

\section{d. Internalization}

Semua dokumen data, informasi dan knowledge yang sudah didokumentasikan dapat dibaca oleh orang lain. Pada proses inilah terjadi peningkatan knowledge SDM. Sumber-sumber explicit knowledge dapat diperoleh melalui media internet (database organisasi). Surat edaran/surat keputusan, papan pengumuman dan internet serta media massa sebagai sumber eksternal. Explicit knowledge digunakan sebagai inspirasi untuk mendapatkan tacit knowledge yang baru. 


\section{HASIL DAN PEMBAHASAN}

\subsection{Kebutuhan Pengembangan}

\section{Use Case Diagram}

Use case adalah deskripsi fungsi dari sebuah sistem dari perspektif pengguna. Dan juga penjelasan dari apa yang dilakukan oleh aktor-aktor yang terlibat dalam perangkat lunak yang dibangun.

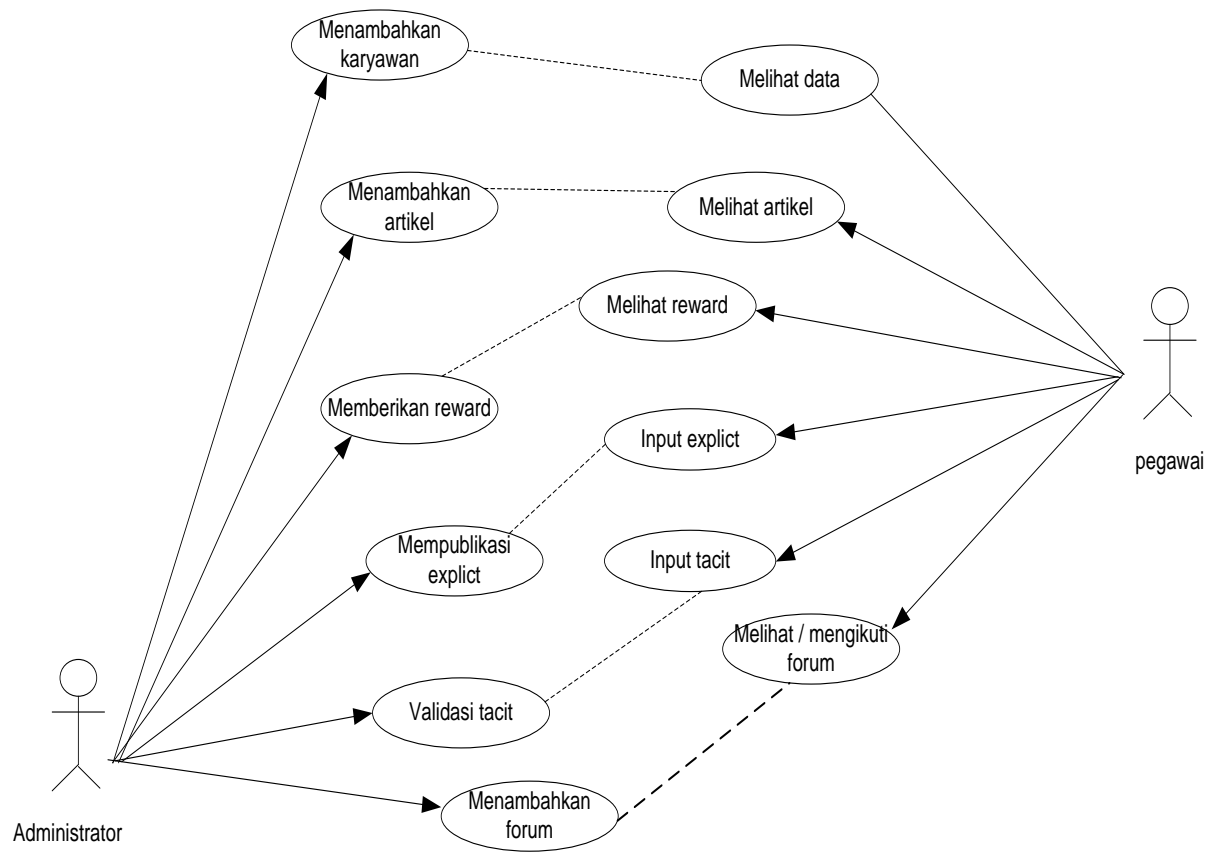

Gambar 3. Use Case Diagram Aplikasi

\section{Activity Diagram}

Diagram aktivitas atau activity diagram menggambarkan workflow (aliran kerja) atau aktivitas dari sebuah sistem atau proses bisnis menu yang ada pada perangkat lunak. Yang perlu diperhatikan disini adalah bahwa diagram aktivitas menggambarkan aktivitas sistem bukan apa yang dilakukan aktor, jadi aktivitas yang dapat dilakukan oleh sistem. 
Gambar 2.3 Rancangan Activity Diagram Untuk Menampilkan Artikel

\subsection{Hasil Pengembangan}

Hasil pengembangan berupa suatu aplikasi yang mendukung penerapan knowledge management system pada rumah sakit muhammadiyah. Aplikasi ini diharapkan dapat membantu pihak administrasi rumah sakit muhammadiyah dalam pengetahuan tersebut kedalam suatu wadah serta meningkatkan budaya knowledge sharing. Penerapan knowledge management system pada bagian administrasi pelayanan rumah sakit muhammadiyah ini adalah hasil akhir dari semua kegiatan dan pengembangan system dengan metode 10 step knowledge management system dari amrit tiwana yang telah diuraikan pada bab sebelumnya. Dari beberapa pengguna user kita akan bahas satu persatu kegunaan dari setiap halaman yang di buat berikut halaman interface KMS rumah sakit muhammadiyah :

1. Halaman Home

Halaman ini merupakan halaman utama setelah selesai pegawai melakukan login, pada halaman ini menampilkan Pelayanan yang ada di Rumah Sakit Muhammadiyah.

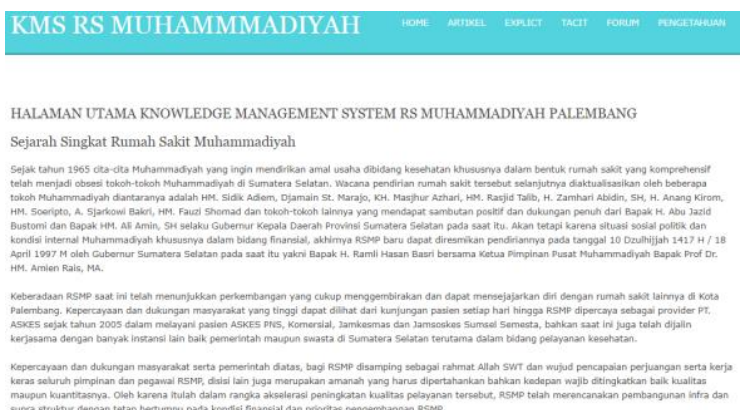

Gambar 4. Halaman Home 


\section{Jurnal Pengembangan Sistem Informasi dan Informatika}

Vol. 1, No. 3, July 2020 e-ISSN: 2746-1335

http://journal.jis-institute.org/index.php/jpsii/index

2. Halaman Artikel

Halaman Artikel digunakan untuk menampilkan Artikel yang diunggah oleh admin. Pada halaman ini dapat dilihat oleh karyawan administrasi Rumah Sakit Muhammadiyah.

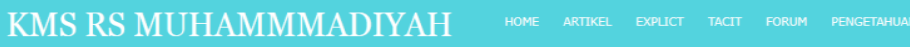

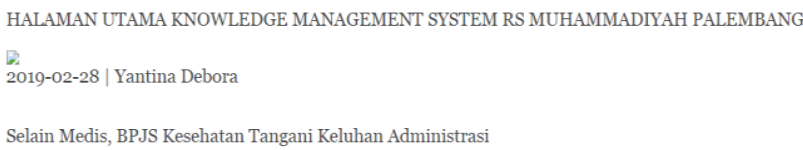

Gambar 5. Halaman Artikel

3. Halaman Explict

Halaman explict ini merupakan halaman yang menampilkan data explict yang diunggah oleh pegawai serta dapat mencari dan mendowload file tersebut.
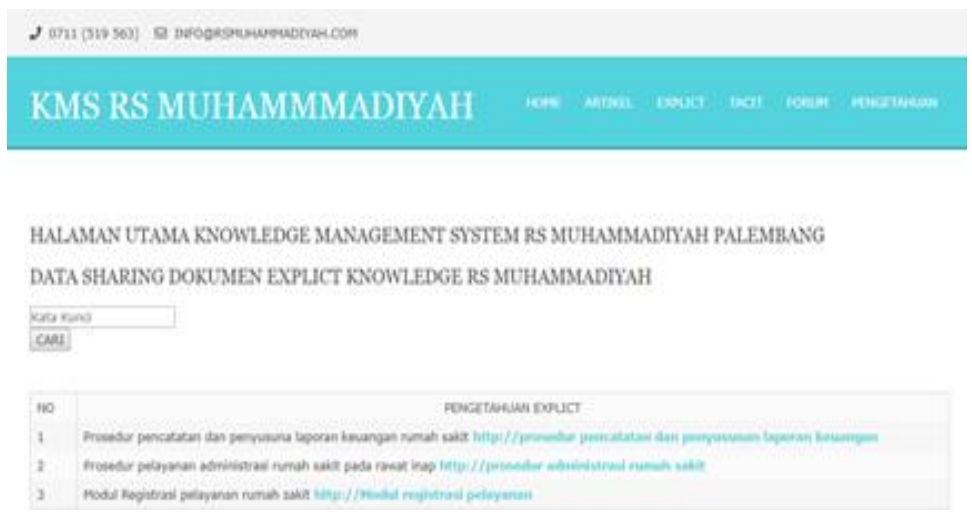

Gambar 6. Halaman Explict

4. Halaman Tacit

Pada halaman ini digunakan untuk menampilkan data tacit karyawan dan dibagikan kepada karyawan yang membutuhkan 
Jurnal Pengembangan Sistem Informasi dan Informatika

Vol. 1, No. 3, July 2020 e-ISSN: 2746-1335

http://journal.jis-institute.org/index.php/jpsii/index

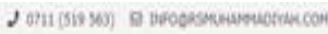

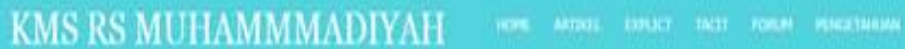

\section{HALAMLN UTAMA KNOWLEDGE MANAGEMENT SISTEM RS MUHAMMADTYH PALEMBANG}

DATA SHARANG DOKUMENTACTT RS MUHAMMLADIYAH

ous

10.

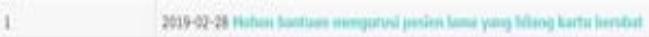

Gambar 7. Halaman Data Tacit

5. Halaman Forum Diskusi

Halaman forum diskusi digunakan untuk berdiskusi dan sharing antar karyawan
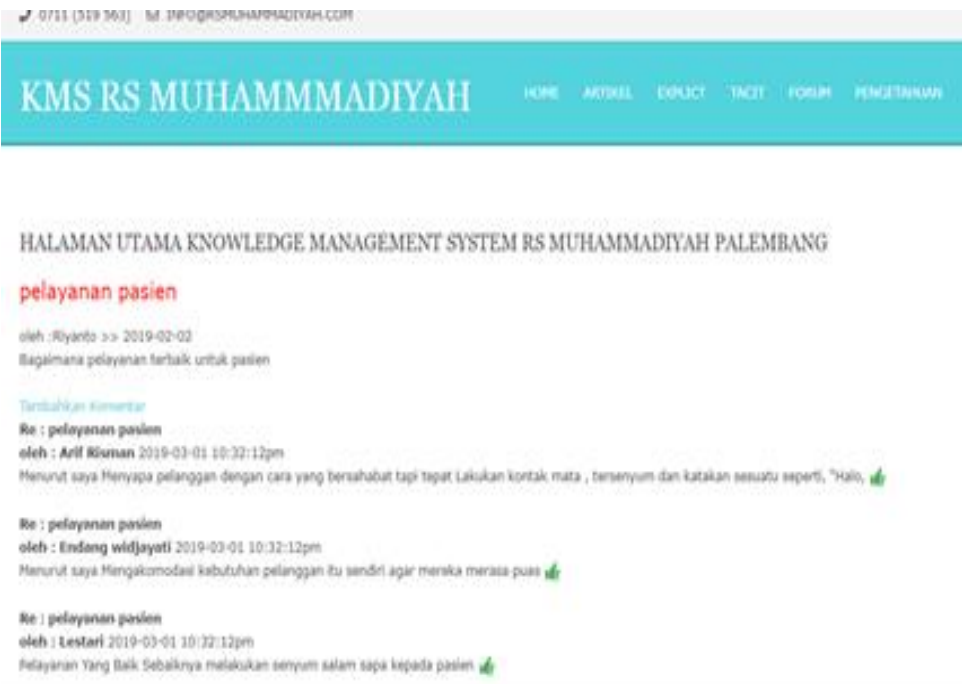

Gambar 8. Halaman Diskusi

6. Halaman Cari Knowledge

Halaman ini digunakan untuk mencari knowledge yang ada dalam Kms rumah sakit muhammadiyah Palembang 
Gambar 9. Halaman Cari Knowledge

7. Halaman Login Admin dan Karyawan

Halaman ini diguanakan untuk admin dan karyawan untuk login

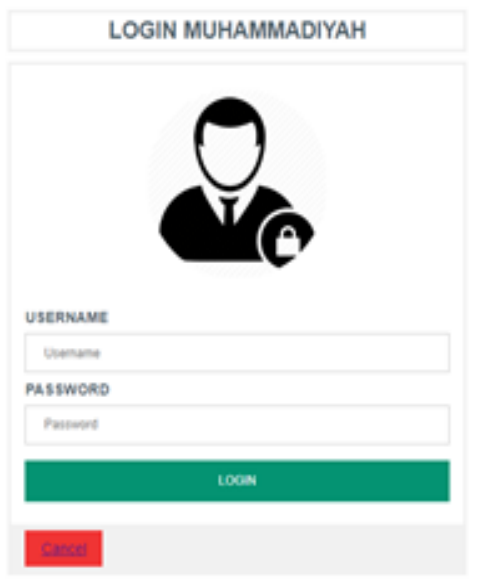

Gambar 10. Halaman Login Admin dan Karyawan

\section{KESIMPULAN}

Berdasarkan penelitian yang dilakukan,dapat disimpulkan:

1. Penelitian ini berhasil membangun sebuah knowledge management system pada rumah sakit muhammadiyah Palembang sebagai bentuk penerapan KMS bagian administrasi

2. Aplikasi yang dibangun dapat membantu karyawan atau pegawai bagian administrasi pelayanan dalam mengumpulkan pengetahuan tersebut kedalam suatu wadah sehingga para karyawan atau pegawai tidak kehilangan pengetahuan yg dimiliki karyawan. 


\section{DAFTAR PUSTAKA}

Arief M Rudianto. 2011. Pemrograman Web Dinamis menggunakan PHP dan $M y S Q L$. C.V ANDI OFFSET. Yogyakarta.

Budi Winarno. 2012. Kebijakan Publik Teori, Proses, dan Studi Kasus. Yogyakarta: CAPS

Djojodibroto, D. 2009. Respirologi (Respiratory Medicine). Jakarta : EGC.

Gurteen, D. 2016. Creating a Knowledge Sharing Culture. Journal Guerteen. New York.

Hakim, Lukmanul, 2008, Membongkar Trik Rahasia Para Master PHP, LOKOMEDIA, Yogyakarta.

Harsono ,Hanifah 2002. Implementasi Kebijakan dan Politik. Yogyakarta:Rinheka Karsa.

Hoof and weenen. 2004. Committed to share: Commitment and CMC Use as Antecedents of knowladge sharing.

Jaan H. dan Lantu, Donald C. 2006. Knowledge Management dalam Konteks Organisasi Pembelajar. SMB-ITB, Bandung.

Nawawi, Ismail. 2012. Manajemen Pengetahuan (Knowledge Management). Ghalia Indonesia. Bogor.

Nurdin Usman. 2002. Konteks Implementasi Berbasis Kurikulum. Jakarta: PT Raja Grafindo Persada.

Tobing. Paul L, 2007, Knowledge Management Konsep, Arsitektur dan implementasi, Yogyakarta : Graha Ilmu.

Yuhefizar. 2008. "10 jam Mengenal Internet Teknologi dan Aplikasinya". Penerbit PT Elex Media Komputindo : Jakarta. 